\title{
Driving Shaft Fatigue Life Determination According to Turkish Mission Profiles
}

\author{
Arif Senol Sener** \\ *Department of Mechanical Engineering, Faculty of Architecture and Engineering, Istanbul Gelisim University, Avcılar, \\ Istanbul, Turkey. \\ (assener@gelisim.edu.tr)
$\$$ Corresponding Author; Arif Senol Sener, Department of Mechanical Engineering, Faculty of Architecture and Engineering, Istanbul Gelisim University, Avc1lar, Istanbul, Turkey. Tel: +90 212 422 7000, Fax: +90 212422 7401, assener@gelisim.edu.tr

Received: 14.03.2016 Accepted: 19.03.2016

\begin{abstract}
In this study, a questionnaire was used to determine the average customer usage of the light commercial vehicles in Turkey. Approximately on 50 road routes and on rough roads in Turkey, the fatigue characteristics of the road profiles were measured by a many sensors equipped on LCV (Light Commercial vehicle).This article focuses on defining the general load spectrum of Turkey roads belong to the driving shaft. Rain-flow statistical counting method was applied driving shaft's signals in order to make fatigue comparisons meaningfully and other application. Fatigue analysis of the driving shaft according to MP (Turkish mission profiles) were calculated by using FEA (Finite Element Analysis) and verified by the Palmgren-Miner rule.
\end{abstract}

Keywords: Customer usage driving shaft, finite element analysis, fatigue analysis, Palmgren-Miner Rule.

\section{Introduction}

Typical automotive design requirement are include the following: high stiffness, good fuel efficiency, smooth ride and handling, occupant comfort, drive characteristics. These requirements must be achieved along with adequate durability and reliability of the vehicle within the warranty timeframe [1]. Durability deals with the material fatigue. This kind of defect can be encountered on old or high millage vehicles. The durability of the vehicles depends on three important parameters: design geometry, material properties and loading environment. One of the parameters of loading environment is road roughness. It is well known that under normal conditions, vehicles are exposed to occasional high loads. It is important to have accurate statistical descriptions of these loads which are often caused by road irregularities [2, 3]. Road quality can vary dramatically from country to country. As such automobile manufactures should set quality and durability design constraints in accordance with customer expectations in the target market. To take preventive action on durability defects, which can occur due to weak design and process, manufactures need accelerated fatigue tests and simulations methods. Durability tests are necessary to adapt vehicle performance to customer expectations [4].

Today, automobile manufactures use four durability test methods: fatigue analysis based on Finite Element Analysis
(FEA), test rigs, test benches (one particular actuator test), and a accelerated test tracks. The most popular method is used for the determine load spectrum for the whole life of vehicle is customer usage based methods. FEA-based fatigue analysis can be performed in a very short time period and can provide a convenient design solution $[5,6]$. To meet these requirements, an important activity in a modern development process is the use of calculation and simulation at an early stage. Computer aided engineering (CAE) is playing an increasingly important role in predicting vehicle characteristics and simultaneously replacing physical test.

In the previous studies about the driving shaft, in 2011, a fuel cell vehicle's driving shaft was investigated by using high performance lightweight materials [7]. In 2006 a fatigue failure of a rear axle shaft of an automobile which has 9 years old was examined in order to understand if the failure was caused by fatigue failure by Asi.O[8]. In 2009 maximum torsion capacity of a hybrid aluminum/composite drive shaft was examined with FEA by S.A.Mutasher [9]. In 2007 fracture and stress analysis of a universal joint and a drive shaft of an automobile power transmission system was done with FEA and by H.Bayrakceken et. al. [10]. In 2008 a failure analyses of elevator of driving shaft was analyzed using FEA and the reason of the fatigue failure was determined by A.Goksenli and I.B.Eryürek [11]. In 2008 fatigue stress fracture of a drive shaft of a caterpillar was searched by FEA and also metallographic examination in 
order to determine real cause of the damage by E.Rusunski et al. [12].

One example of a customer usage study; Tractor usage aim on wet and dry ground and also tractor usage for agriculture and non-agriculture and regional usage aim distribution were determined in India from E.T.E.C. (Eicher Tractors Engineering Centre) and A.R.I.A. (The automotive Research Association of India [ 13].

Another example is a customer usage study performed by FIAT Co. for Brazilian and Italian markets. As it is well know that Brazil and Turkey haven't special proving ground in order to make test on standard fatigue road for the development of the new car models. During the research FIAT Co. compared proving ground profiles effects of Italy and Brazil's public roads including customer usage effects on the vehicles by using frequency based fatigue life [14].

The next example is of a customer usage study was done by FIAT Co. AMOA (automobile mode of operation systems) on Ritmo 60 and Tipo1372 DGT [3, 15].

And one of the other example is of customer usage study was performed by TOFAS A.Ş. for defining Turkish customer vehicle usage profile and fatigue characteristic effect of Turkey's road profiles on a light commercial vehicles[16,17].

Differences of this study;

- Firstly, Turkish customer automobile usage profiles were determined by questionnaire method. Holiday time and the distance lived from the home which is the one of the parameter of the questionnaire has been done by FIAT in 1993[3, 15]. FIAT had accepted the holiday concept as the interval of holiday more than three days and if the distance is far away more than $300 \mathrm{~km}$ from the residence area. In our study the holiday concept is restudied and holiday interval was decreased from one week to three days and the holiday distance was accepted $300 \mathrm{~km}$ from the residence area were applied on the Turkish customer in 2001 as a questionnaire[16].

- Secondly, on the other studies road roughness fatigue characteristic effects on the vehicle were acquired both from the public roads (city roads, intercity, mountain and highway) and also mixed some special proving ground data. But in this study, the road roughness data were acquired only from public roads and instead of special proving ground effects very heavy village roads including mostly potholes and sharp curves and rocked bad road profiles were added due to the lack of standard proving ground in Turkey.

The road fatigue characteristics were measured totally from one city to another city since to make a comparison on different roads effect. The design of test roads is extremely important for accurately simulating vehicle life. In the following section a methodology for defining test roads for a light commercial vehicle is explained.

\section{Methods and Analysis}

Durability tests for a vehicle or component must simulate the entire load spectrum (MP: mission profile, Turkish general road characteristics) experienced during normal usage. This means that the load spectrum must cover all anticipated tasks and conditions during the lifetime of the vehicle $[18,19]$. The service life of a vehicle component largely depends on the loading conditions during usage [19].

For design and test purposes, it is necessary to define a representative loading spectrum, which should be used for design evaluation as well as for derivation of a load spectrum for durability tests $[18,19]$. Today there are two methods used to determine customer usage are the questionnaire and black box method.

\subsection{Black Box Method}

The black box system is based on an electronic "black box" which has the same size as a car radio set and is trouble free for the users which are fitted to a number of cars of preferential users selected by stratification criteria. A lot of data were measured and directly recorded in digital form on static storage $[3,15,20]$.

\subsection{General Description of a Questionnaire Method}

This method implements a large telephone survey designed to acquire information about the distribution of route types (city, extra urban, mountain, highway) the distribution of loads (driver without loads, driver and half load, driver and full load) customer education level, and the purpose of vehicle usage etc.[3,19,21]. After acquiring the questionnaire results, a road test simulation is performed to collect data with an equipped vehicle or several equipped vehicles on public roads and special proving ground, during various maneuvers (braking, curving, accelerating), during power generation (engine and transmission components, in various location, on various type of roads (city, intercity, mountainous, rural), and by a test driver or multiple test drivers $[3,19]$. Then the collected row data are subjected to data processing like spike, filtering, manipulating etc. Then the signals are divided according to road type and load condition. Data processed road excitation signals are transformed into normalized unit values. Then each road signal is subjected to statistically counting method 3D matrix or $2 \mathrm{D}$ range. So it is possible to make comparison of each road signal for each sensor. By multiplying the questionnaire with road type and target $\mathrm{km}$, it is easy to form the target mission profile. The target mission profile ( which consists of road excitation signals taking into account $90^{\text {th }}$ percentile distribution of customer automotive usage, load, and the target of MP for the light commercial vehicles is 200000 $\mathrm{km}$ ) is obtained for each sensor [16]. The methodology is based on the following principle, if the same inputs are reproduced, then same damage will occur [21].

After forming MP, it is then possible to find mixes of tracks or rig drivers that match to the inputs for accelerated test including track or test rig that are corresponding to the same damage effect of MP. If the same inputs are maintained, matrix calculation of various forms will provide a scheme for assessing the mixture of road excitation signals, and for optimizing the test length or test time. 
$\mathrm{A}[\mathrm{X} 1]+\mathrm{B}[\mathrm{X} 2]+\mathrm{C}[\mathrm{X} 3]+\ldots \ldots \ldots \ldots \ldots+\mathrm{Z}[\mathrm{Xn}]=[\mathrm{Y}]$

Where;

A, B, C ....Z : Multipliers of test data

$[\mathrm{X} 1],[\mathrm{X} 2] \ldots \ldots \ldots . . . . \mathrm{Xn}]$ : Matrix of test measurements

$[Y]$ : Matrix of customer target measurements.

This can be interpreted quite easily as: A times track X1, followed by times track $X 2$, and so on, so that it gives the same effect as $y$ of the target [21].

\section{Application Examples}

In this study for road test acquisitions one FIAT Doblo Passenger car LCV was selected and it was designed for transportation of goods and passengers. The algorithm of the study is presented in Fig.1

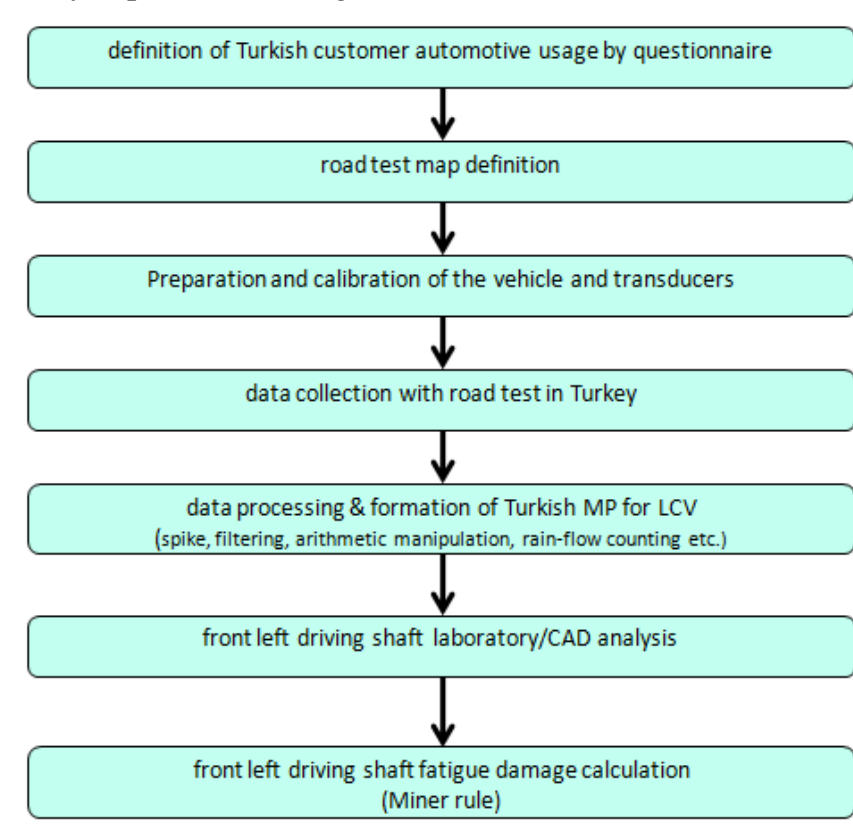

Fig. 1. Algorithm of the study

\subsection{Definition of the Turkish Profile -Questionnaire Application.}

Because the questionnaire method allows a faster data collection, provides flexibility on data elaboration and reduces cost compared to the black box method. As such, it was the method of choice in this study. The Turkish customer usage profile of a LCV that is used for transporting both goods and passengers was developed based on a questionnaire administered to Turkish customer with my support and also with the support of automotive dealers representing the LCV manufacturer.

\subsection{Definition of the Turkish Profile-Definition of Road Map}

The test road map represents $90 \%$ of customer usage in Turkey. Roads were divided in four groups: city road usage was found to be more common around the Istanbul district; Mountain roads were more common in the Black Sea region.
Intercity roads, which include hot climatic and curved road condition, were found around the Mediterranean Sea. Roads in Central Anatolia were characterized by high altitudes, hot temperatures, and long distances between cities. For the highway road characteristics Istanbul-Ankara and Adana Gaziantep roads were subjected to data acquisitions. Those test roads in the road test map was designed taking reference of the sale percentages of LCVs according to region, customer complaints, previous model experiences, climatic conditions, and geography $[16,17]$. The test road map formed taking reference above information for data acquisitions is presented in Fig. 2 .

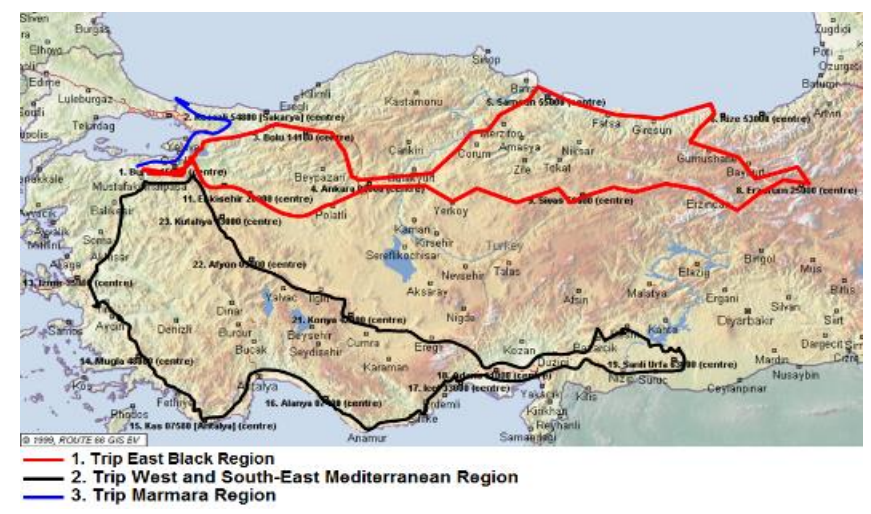

Fig. 2. Road test map

\subsection{Definition of the Turkish Profile-Data Acquisition to Define the Mission Profile Target}

In this study, the measurements were carried out with a vehicle equipped with sensors and driven over customers on chosen roads by an expert test driver and an engineer at full loads. For data acquisition and fatigue simulation, a vehicle was equipped with load transducers, two strain-gauges on the leaf spring, one strain-gauge on driving shaft, and one straingauge on the steering wheel rod. The driving shaft torsion torque loads created by maneuvers, breaking and acceleration were measured by strain-gauges on the driving shaft. The mounted strain gauge on the driving shaft in order to measure torsion torque data is demonstrated Fig.3.

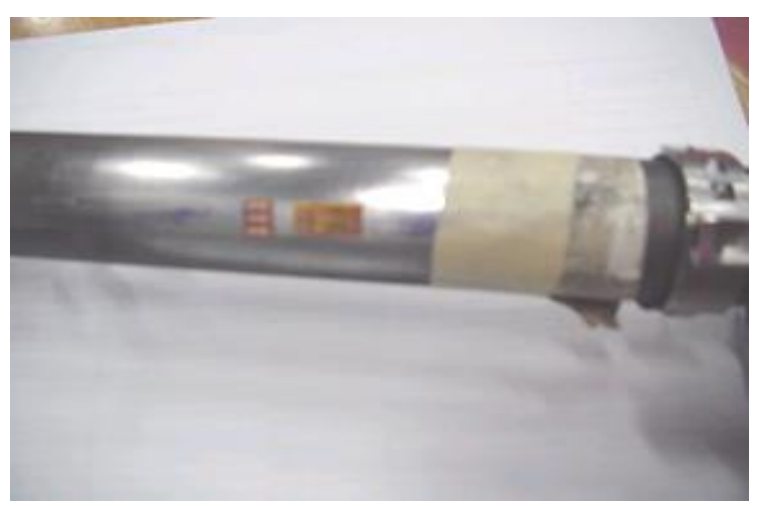

Fig. 3. Strain-gauge mounted on driving shaft in laboratory

The strain-gauges calibration on the front left driving shaft is presented In Fig. 4 and the other transducers, sensors and strain-gauges were prepared, calibrated and analyzed in the laboratory before being assembled on the car. 


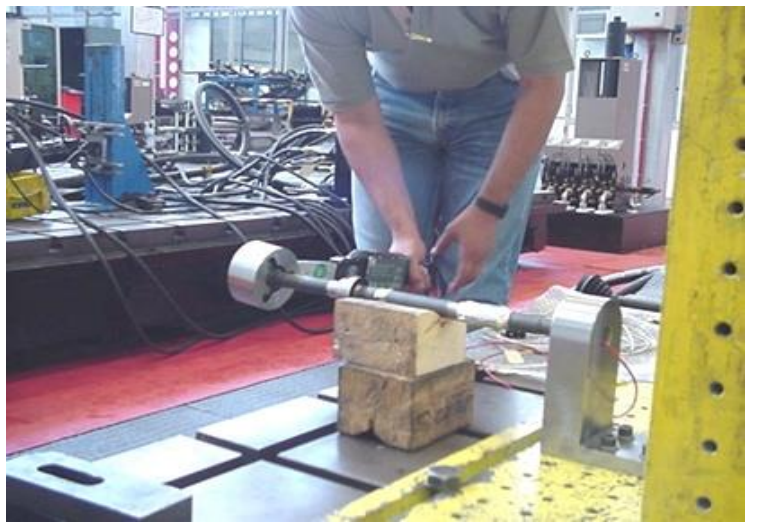

Fig. 4. Strain-gauge mounted on driving shaft in laboratory

\subsection{Data Processing}

For fatigue data collection at time domain, we could not measure external loads directly. Instead of that we measured their reactions at certain points of vehicle parts [22]. The collected signals were processed by spike analysis, frequency analysis, filtering, arithmetic manipulation and statistical counting operation [23]. The algorithm of the data elaboration process is presented in Fig.5

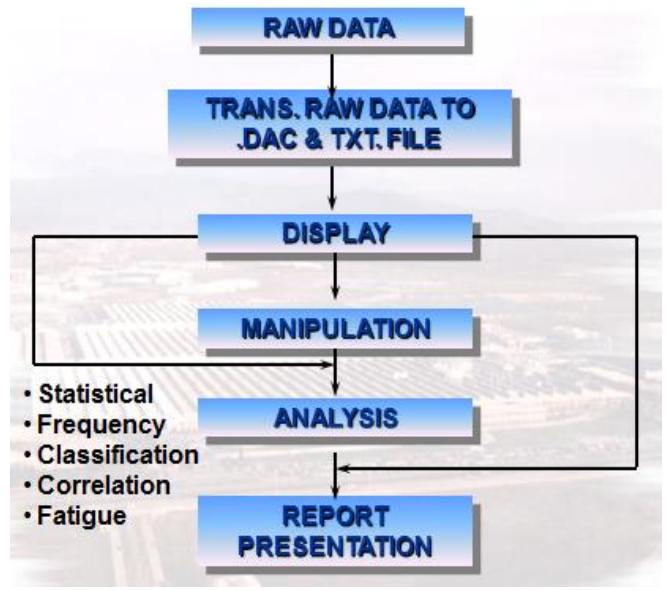

Fig. 5. Algorithm of the data elaboration process

Spike Analysis: During data acquisition some "spikes" which were occurred due to environmental and physical factors, were eliminated by visual and statistical methods [23]. A sample spike elaboration analyses of the signal is presented in Fig.6.

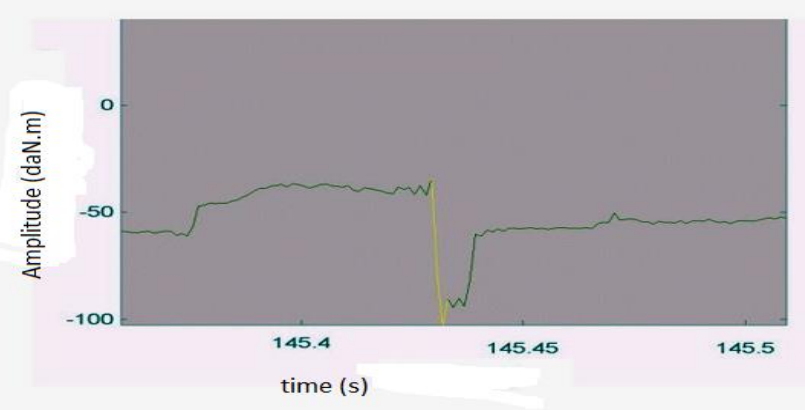

Fig. 6. Algorithm of the data elaboration process
Filtering: As it is known that vehicle suspension parts frequency range of interest for fatigue analyses is between 40 $\mathrm{Hz}$ and $60 \mathrm{~Hz}$. For road simulation, it is generally accepted that excitation over $100 \mathrm{~Hz}$ can be neglected [24]. ]. Above $100 \mathrm{~Hz}$ frequencies in the original data were removed by means of a low-pass filter is presented in Fig.7[16,17,23,24].
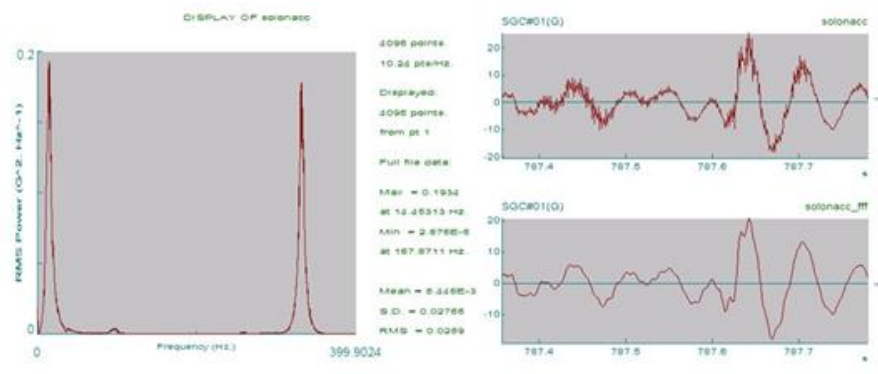

Fig. 7. Low- pass filter application on the driving shaft signals

Arithmetic Manipulations: In this study, acquired each test data which is not useful for fatigue life calculation is extracted before the vehicle movement [23].

Statistical Road Excitation Signal Counting: The road signal is formed by random and stationary signals that are time- varying. Time -varying signals should be converted to an equivalent value independent of time for comparison. The statistical counting method was applied to achieve this conversion [25].The driving shaft strain-gauge data were reduced to foreseen $200.000 \mathrm{~km} \mathrm{MP}$ values using the rainflow statistical counting method taking into account mean amplitude of the driving shaft torsion data [25,26].

Forming Mission Profile Target: As the each acquired data had different lengths, the each measured data was normalized to convenient distance in kilometers (i.e., $1 \mathrm{~km}$ or $10 \mathrm{~km}$ ) in order to compare and extrapolate for MP [15, 16, 21]. Each normalized measurement was classified according to road type (city, intercity, mountain, and highway), each road type was averaged within its class. Then each classified measurement was extrapolated to the estimated target $\mathrm{km}$ of MP and then multiplied by the percent Turkish customer usage distribution which the given road type based on the questionnaire. The histogram of driving shaft torsion data MP (Turkish customer automobile usage fatigue characteristic of driving shaft for $200.000 \mathrm{~km}$ ) is showed Fig. 8 .
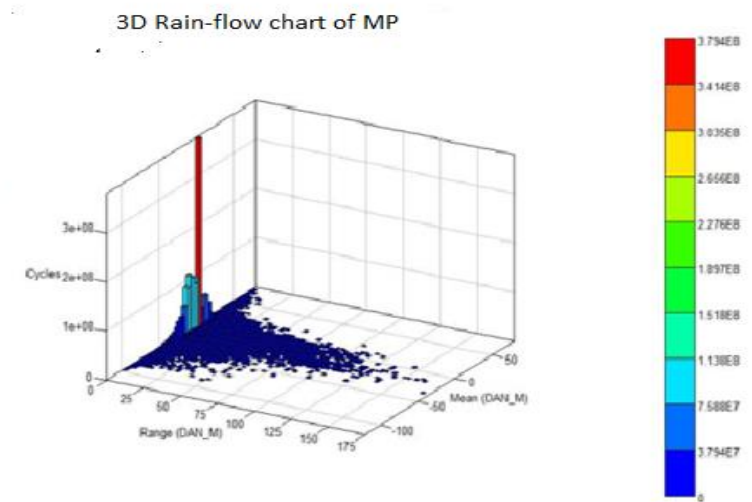

Fig. 8. Driving shaft Mission Profile rain-flow histogram $(200.000 \mathrm{~km})$ 


\section{Simulation of Experimental Data by Finite Element Analysis}

\subsection{Driving shaft CAD model}

The CAD model of the driving shaft was designed in SOLIDWORKS software program is presented in Fig.9 [27].

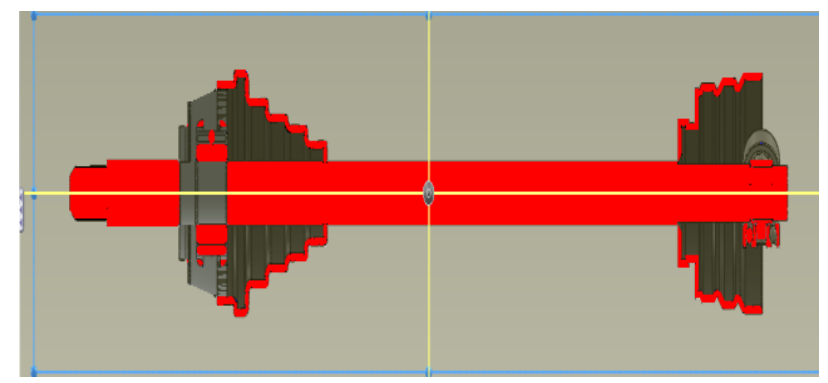

Fig. 9. CAD model of driving shaft

Then 3D CAD model of the driving shaft was exported to ANSYS program to perform FEA analysis. 3D CAD model of driving shaft was formed from 155187 tetra hexagon elements and 253739 nodes is presented in Fig. 10 [28].

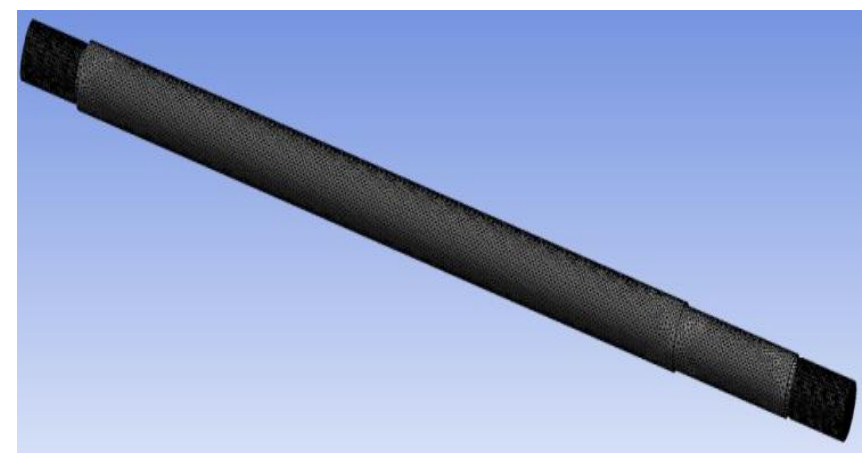

Fig. 10. FE Model of the driving shaft

\subsection{Boundary Condition}

The boundary condition of driving shaft is presented is presented in Fig.11. As it can be seen from the picture, the red rotating arrow demonstrate the applied torsion torque from the gearbox side which is allowed free only rotation axis while the other wheel side of the driving shaft teeth which is demonstrated with blue arrow is nailed tightly crosshead with bearing inside of spindle which is connected to axon with a bold is demonstrated and the fixed point was not allowed freely both rotation and shift every three axis [28].

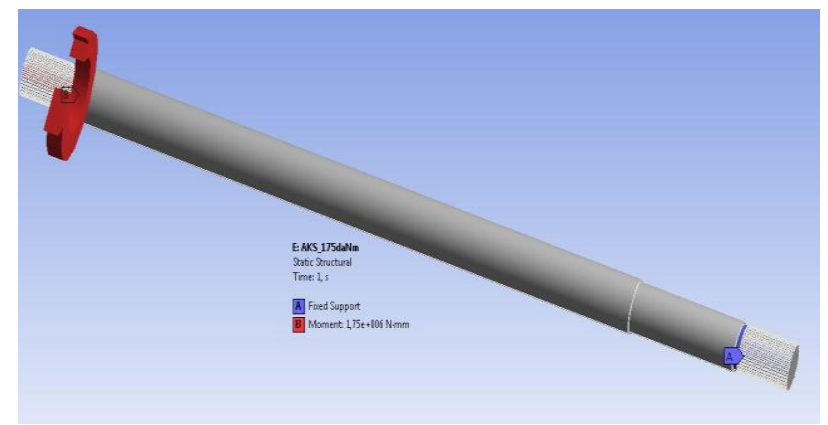

Fig. 11. F. Boundary conditions of the driving shaft

\subsection{Static and Fatigue Analysis}

The linear static analysis of the driving shaft was executed using the most critical load that was acquired during road tests in Turkey is shown in Fig.12 [16].

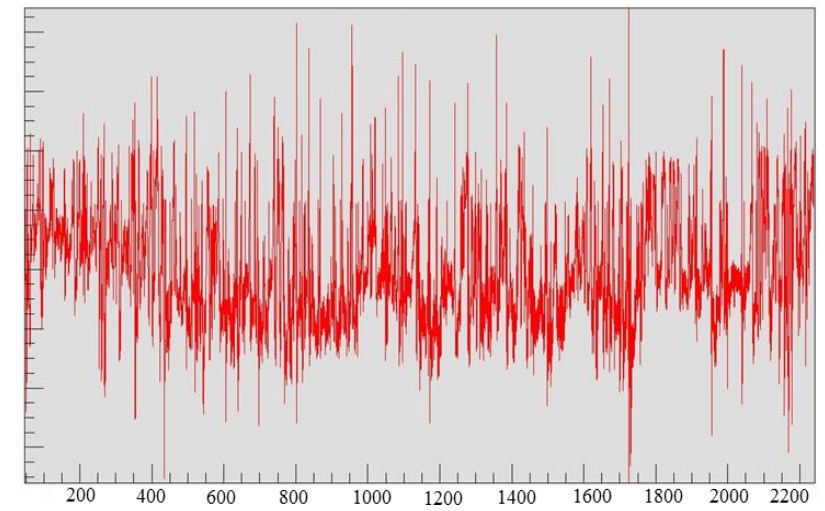

Fig. 12. Critical road data torque -time signal of driving shaft

For the statistical analysis of the driving shaft, the maximum load data, measured during the road test, was applied as torsion at side of the gear box approximately 175 daN.m by using the FE model. After applying 175 daN.m torques in torsion axis $0.0174_{\mu \gamma}$ angular strain was derived is presented in Fig.13. At the same time the maximum shear stress was found $1397 \mathrm{Mpa}$ at node 5796 according to the von-Mises method using the most critical load condition in the linear static analysis. [29].

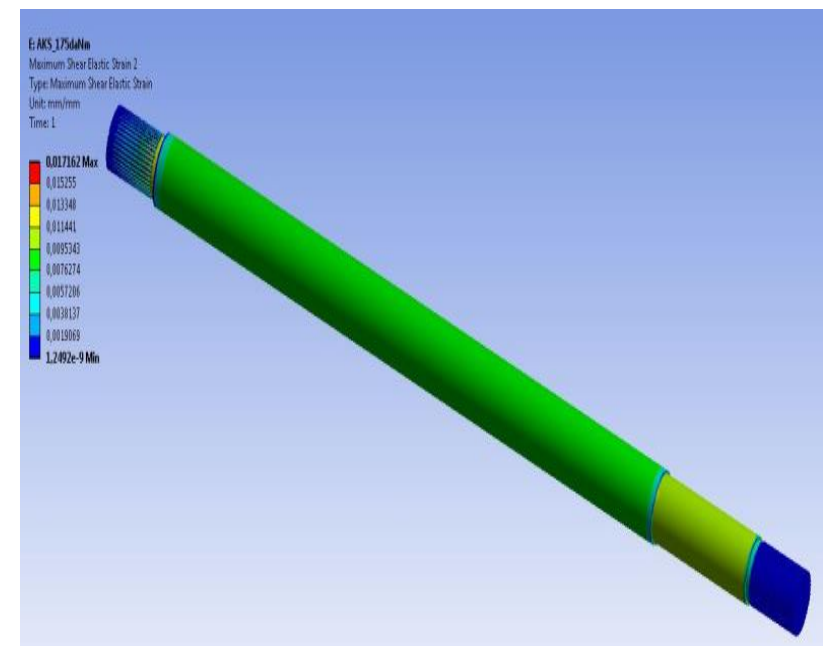

Fig. 13. Static strain analysis of driving shaft according to 175 daN.m torque

The driving shaft real bench test and CAD static analysis strain values comparison is presented in Fig.14. As it can be seen from the graphics that vertical axis demonstrates physically applied torque loads whereas axial axis demonstrates derived angular unit strain on the driving shaft in laboratory and CAD during calibration test. Square symbol demonstrate us physically applied torsion moment on the driving shaft in lab while triangle symbol shows us the CAD static analysis result after applying same loads on the FE model of driving shaft. When 100 daN.m is applied $0.00872 \mu \gamma$ by the physical test, $0.0098 \mu \gamma$ by the computer analysis test were measured 


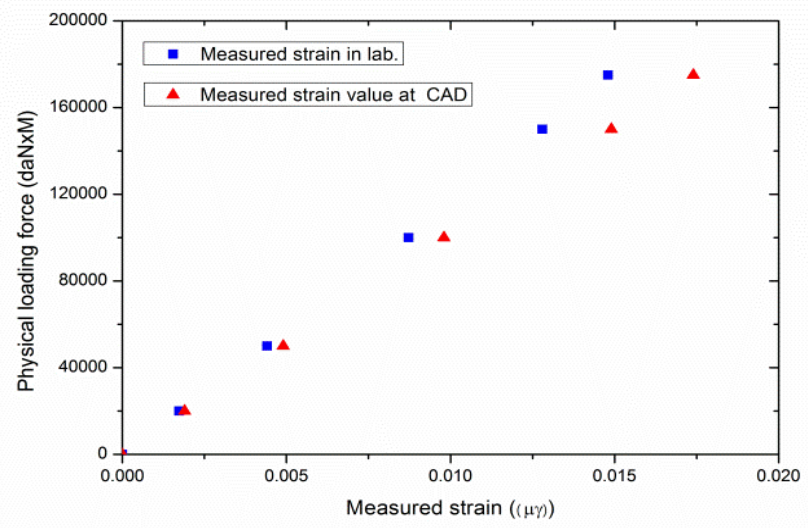

Fig. 14. Driving shaft real bench test and CAD static analysis strain values comparison

The maximum stress is much lower than the actual yield stress of the driving shaft material yield stress. The S-N method was preferred because the values obtained of the data of different kind of the roads in Turkey are much lower than the material yield stress $[16,30]$. The Wohler line $S$ (stress) $\mathrm{N}$ (number of cycles) of the material characteristics of the driving shaft is shown in Fig. 15.

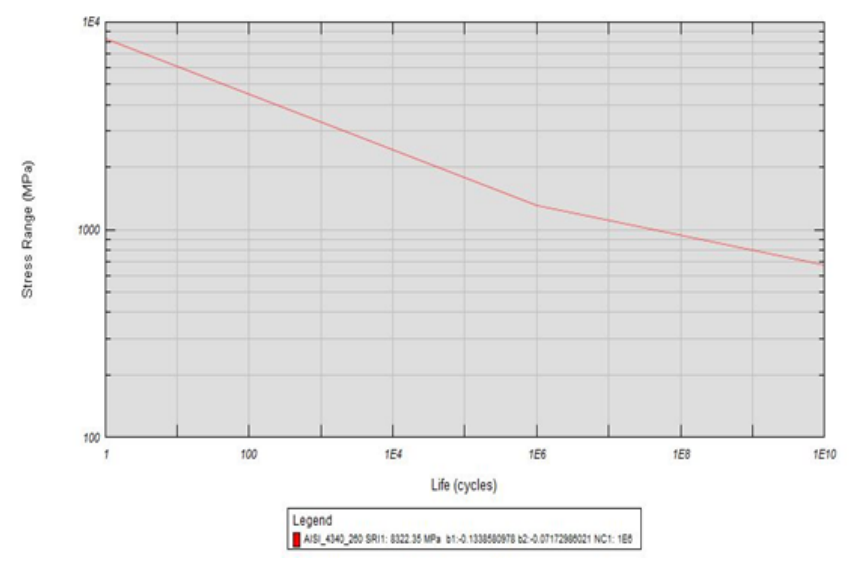

Fig.15. S-N curve of the driving shaft material

\subsection{Palmgren-Miner Analysis}

Miner's rule is one of the most widely used cumulative damage models for failures caused by fatigue. This linear damage concept in a fatigue setting by considering the situation where a component is subjected to $\mathrm{n}_{1}$ cycles at alternating stress $\sigma_{1}, \mathrm{n}_{2}$ cycles at stress $\sigma_{2}, \ldots, \mathrm{n}_{\mathrm{N}}$ cycles at $\sigma$ $\mathrm{N}$. From the $\mathrm{S}-\mathrm{N}$ curve for a material, then it is possible to find the number of cycles to failure, $\mathrm{N}_{1}$ at $\sigma_{1}, \mathrm{~N}_{2}$ at $\sigma_{2}, \ldots$, $\mathrm{N}_{\mathrm{N}}$ at $\sigma_{\mathrm{N}}$.It is reasonable in this case to let the fractional damage at stress level $\sigma_{i}$ be simply $\mathrm{n}_{\mathrm{i}} / \mathrm{N}_{\mathrm{i}}$, so that the Palmgren-Miner rule would say that fatigue failure occurs $\sum_{\text {when }}^{N} \frac{n_{i}}{N_{i}} 1$ [31].

In this study the Palmgren-Miner rule was applied.

\section{Results}

From the questionnaire Turkish customer automotive usage for LCV is defined. When the derived data are compared to one of the European countries, the major difference is found in the amount of city usage, which is 50 $\%$ in Turkey. The primary purpose of aim of usage of LCV in Turkey is for work-work travel. Table 1 shows Turkish customer aim of usage of LCV [16].

Table 1. Turkish customer aim of usage of LCV

\begin{tabular}{|l|l|}
\hline Home-work-home & $29 \%$ \\
\hline Work to work & $55 \%$ \\
\hline Shopping and leisure & $4.7 \%$ \\
\hline Weekend & $5,4 \%$ \\
\hline Holiday & $5,5 \%$ \\
\hline
\end{tabular}

The 2D Turkish mission profile for driving shaft data in horizontal axis cycle and in vertical axis torsion torque is presented in Fig.16. From the MP test in Turkey 175 daN.m like the maximum torque load is reached.

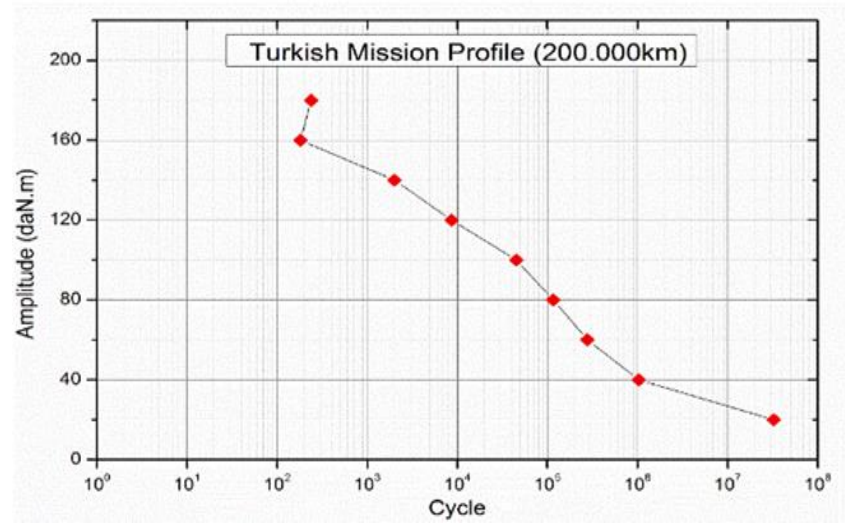

Fig. 16. Turkish mission profile driving shaft data for $200.000 \mathrm{~km}$

Fatigue CAD analysis of driving shaft in terms of fatigue life is shown in Fig.17. Fatigue damage isn't occurred.

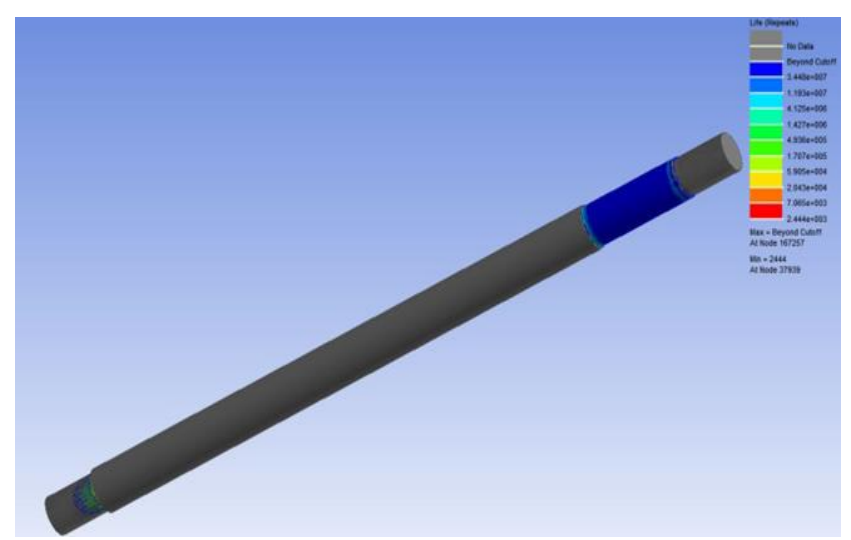

Fig. 17. Fatigue life of driving shaft applied MP data $200.000 \mathrm{~km}$ 


\section{Conclusion}

In this study, Turkish customer usage profile was developed based on a questionnaire handed out to Turkish light commercial vehicle users [8]. A comparison of LCV automobile usage between a European country and Turkey was presented. This revealed that the Turkish customers use this type of vehicle for city driving twice as much as typical users in a European country [16].

The primary purpose of light commercial vehicle usage in Turkey is work-work and work-to-home travel. A mission profile of LCV usage specific to Turkish drivers was developed. After processing, classifying and normalizing different signals, a mathematical mission profile (200.000 $\mathrm{km}$ for a typical Turkish customer) was calculated. Fatigue road test were performed by applying computer aided fatigue method to data measured by several vehicle mounted sensors $[16,17]$.

Based on this analysis, critical force and stress ranges have been defined and recorded in a database for future reference during development projects. Tetra and hexa type $3 \mathrm{D}$ elements have been used in FEA models. Tetra type elements were found to give more precise results in terms of frequent and geometrical aspect for the teeth of the driving shaft. The linear analysis method that is used in virtual analysis of the structure gave more precise results for this kind of driving shaft.

Due to the fact that the number of cycles was quite low, and it was seen that the $\mathrm{S} / \mathrm{N}$ fatigue method was more suitable. It has been verified that there was no fatigue damage occurred on the driving shaft after applying the Turkish customer profile.

It has been observed that computer aided analysis can be used as an alternative for laboratory tests because the results that were obtained from both methods were quite similar. Based on these results, using computer aided calculation methodologies it can be seen that it is both cost effective and helpful to develop better and market specific products. The results of this study can also be used for developing new automobile models, before construction of real prototypes and pre-serial production cars..

\section{Acknowledgements}

TOFAS A.Ş. is acknowledged for supporting this research.

\section{References}

[1] P. Heyes, X. Lin, A. Buczynski and M. Brown, "Application of Biaxial Plasticity and Damage Modeling to the Life Prediction and Testing of Automotive Components", '5 th International Conference on Biaxial /Multiracial Fatigue and Fracture Cracow, 1997, Poland.

[2] K. Bogsjö, "Development of analysis tools and stochastic models of road profiles regarding their influence on heavy vehicle fatigue", Vehicle system Dynamics, 44:1,780-790.
[3] C. Marchesani, F. Parmigiani and M. Vianello, "Integrated method to define the mission profile of a passenger car", Study Report, FIAT Auto S.p.A.

[4] K. DreBler, M. Speckert, R. Müller and Ch. Wber, "Customer loads correlation in Truck engineering", Berichte des Fraunhofer ITWM, 2009.

[5] MSC. Software GmbH/Fatigue V8 User Manuel, 1998.

[6] K. Ahlin, J. Granlund and F. Lindstrom, "Comparing road profiles with vehicle perceived roughness", International Journal of Vehicle Design, 36(2-3): p. 270286, 2004

[7] S. Zeheng, H. Hu,J. Feng, Z. Zheng, Y. Wang and L. Lu, "Lightweight design of automobile drive shaft based on the characteristics of low amplitude load strengthening", Chinise Journal of Mechanical Engineering, vol. 24, 2011.

[8] O. Asi, "Fatigue failure of rear axle shaft of an automobile", Enginering Failure Analysis, vol. 13, pp.1293-1302, 2006.

[9] S.A. Mutasher, "Prediction of the torsional strength of the hybrid aluminum/composite drive shaft", Material and Design, vol. 30, pp. 215-220, 2009.

[10] H. Bayrakceken, S. Tasgetiren and I. Yavuz, "Two cases of failure in the power transmission system on vehciles: A universal joint yoke and drive shaft", Enineering Failure Analysis, vol. 14, pp.716-724, 2007.

[11] A. Göksenli and I.B. Eryürek, "Failure analysis of an elevator drive shaft", Engineering Failure Analysis, vol. 16, pp.1011-1019, 2009.

[12] E. Rusunski, P. Harnatkiewicz, M. Bobyr and B. Yakhno, "Caterpillar drive shaft damage causes analysis", Archive of Civil and Mechanical Engineering, vol. 8, no. 3, 2008.

[13] P.K. Paul, R.K. Dunga, A. Verma, A.V. Minakar and S. Raju, "Techniques for accelerated design validation of tractor chassis”, SAE Paper 01, pp.1-50, 2001.

[14] D. Filippo, M. Macro, B. Thomas and R.C hristophe, "Structural characterization of vehicle on a rig test versus different road profiles analysis of experimental results", LMS International, vol. 54, pp. 251-258, 2001.

[15] C. Marchesani, F. Parmigiani, M. Vianello, "Integrated method to define the mission profile of a passenger car", FIAT Auto SpA, pp. 45-54, 1979.

[16] Ş.A. Şener, "Fatigue life determination of the leaf spring on the light commercial vehicle according to Turkish Mission Profile", 2003, Istanbul, Turkey.

[17] Ş.A. Şener, "Finite element based vehicle component fatigue life assessment according to a customer usage profile”, Materials Testing, vol. 56, pp. 198-207, 2014.

[18] K. Drebler, M. Speckert, R. Müller and Ch. Weber, "Customer loads correlation in Truck engineering", Berichte des Fraunhofer ITWM, 2009. 
[19] V. Grubisic, "Determination of load spectra for design and testing", International Journal of Vehicle Design, vol. 15, pp.8-26, 1994.

[20] M. Fantacchiotti and M. Vianello, "Gradual improvement of the vehicle reliability up to the target value", FIAT Auto SpA Design Engineering, 1994.

[21] Case Study-Complete Customer Usage Profiling Example Raw Data Through Track Correlation to Accelerated Rig Drive in 4 Days, Iveco, 1999, Italy, UK.

[22] M. Gobbi and G. Mastinu, "Expected fatigue damage of road vehicles due to road excitation", International Journal of Vehicle System Dynamics, vol. 29, no. 1, pp. 778-788, 1998

[23] MSC. Software GmbH nSoft volumes 5.2 User Manuel, 1999.

[24] Ricerca del profilo di Missione vetture segment B Turchia, Turkish Ciklo Relazione Prot. No. 1-1998, D.T.S.V. Affidabilita' e Terreni Prova Laboratorio Misure, Study Report, 1998, Arese, Italy.

[25] ASTM Standard E 1049-85, Philadelphia, 1997, USA.

[26] N.M.W. Bishop, L.W. Lack, T. Li and S.C. Kerr, "Analytical fatigue life assessment of vibration induced fatigue damage", $1^{\text {st }}$ MSC Worldwide Automotive User Conference, 1995, USA.

[27] SolidWorks Software Program, 2011.

[28] ANSYS V 14.5 Software Program, 2012.

[29] MSC Software GmBH Online Help Documentation, 1999.

[30] The Ncode Book of Fatigue Theory, Ncode Technical Reference Book V4.3. Document rel 1.0, 2000.

[31] M.A. Miner, "Cumulative damage in fatigue", Journal of Applied Mechanics, vol. 12, pp.159-164, 1945. 